\title{
Estudo preliminar de adaptação e validação da Escala de Tolerância à Infidelidade
}

\author{
Preliminary study of adaptation and validation of the Tolerance to Infidelity Scale \\ Artigo Original | Original Article
}

\author{
Andreia Filipa Vaqueiro Domingues, PsyM (1a), Mariana Vaz Pires Marques, PhD (1, 2b), Sónia Catarina Carvalho Simões, \\ $\mathrm{PhD}(1 \mathrm{c})$ \\ (1) Instituto Superior Miguel Torga, Coimbra, Portugal. \\ (2) Serviço de Psicologia Médica, Faculdade de Medicina, Universidade de Coimbra, Coimbra, Portugal \\ (a) Esboçou a versão escrita original; contribuiu substancialmente para a conceção e planeamento do estudo e recolheu, analisou e interpretou os dados do estudo. \\ (b) Orientou a versão escrita original; contribuiu substancialmente para a conceção e planeamento do estudo e orientou a análise e interpretação dos dados do estudo. \\ (c) Contribuiu para a conceção do trabalho, reviu criticamente o conteúdo intelectual. \\ Autor para correspondência | Corresponding author: Mariana Vaz Pires Marques. Largo da Cruz de Celas, n¹, 3000-132 Coimbra, Portugal; e-mail: mvpmarques@gmail.com
}

\section{Palavras-Chave}

Avaliação da tolerância à infidelidade Escala de Intolerância à Infidelidade

\section{RESUMO}

Objetivos: Em Portugal, não encontrámos estudos e instrumentos que avaliassem, para a população portuguesa, a tolerância à infidelidade. Este estudo preliminar pretendeu, assim, avaliar e adaptar para a população portuguesa a Escala de Tolerância à Infidelidade e explorar associações entre a tolerância à infidelidade, variáveis sociodemográficas, relacionais e relativas à infidelidade (e seu perdão), autocriticismo e autocompaixão.

Métodos: 223 participantes (sexo feminino, $n=155 ; 69,5 \%$ ), entre os 18 e os 67 anos, preencheram um questionário sociodemográfico e com questões relacionais e relativas à infidelidade, a Escala de Tolerância à Infidelidade, a Escala de Autocompaixão e a Escala das Formas do Autocriticismo e de Autotranquilização.

Resultados: A versão adaptada para a população portuguesa da Escala de Tolerância à Infidelidade mostrou apresentar duas dimensões: tolerância à infidelidade sexual e tolerância à infidelidade emocional. Ambas revelaram boa consistência interna (respetivamente, $\alpha=0,896 ; \alpha=0,878$ ). A tolerância à infidelidade sexual revelou boa estabilidade temporal e a tolerância à infidelidade emocional muito boa estabilidade temporal. Não se verificaram diferenças nas duas dimensões por sexo. Os participantes casados ou em união de facto apresentaram maior tolerância à infidelidade sexual, por oposição com os solteiros, viúvos, separados e divorciados. Quem relatou ter perdoado uma situação de infidelidade apresentou maior tolerância à infidelidade sexual, do que quem não o fez. Já quem afirmou não ter não ter tido dificuldade em fazê-lo, apresentou maior tolerância a ambos os tipos de infidelidade, do que quem expressou dificuldade em perdoar. Conclusões: A versão adaptada da Escala de Tolerância à Infidelidade revelou boa consistência interna (total e subescalas) e boa estabilidade temporal. As associações com o estado civil e sobretudo com as variáveis relativas ao perdão face à infidelidade parecem apontar para a validade da escala, mas são necessários mais estudos que explorem, nomeadamente, a sua validade de construto.

\section{ABSTRACT}

Aims: In Portugal, we did not find studies and instruments that evaluate tolerance to infidelity for the Portuguese population. Therefore, the aim of this preliminary study was to adapt and validate the Tolerance for Infidelity Scale (TIS) for the Portuguese population and to explore the associations between the tolerance for infidelity and different sociodemographic, relational and regarding infidelity (and its forgiveness) variables, selfcriticism and self-compassion.

Methods: 223 individuals (women, $n=155 ; 69,5 \%$ ), with ages between 18 and 67 years old, answered a protocol consisting of a questionnaire with sociodemographic, relational and infidelity questions, the Tolerance for Infidelity Scale, the Self-compassion Scale and the Forms of Self-criticizing/Attacking and Self-Reassuring Scale. Results: The adapted version for the Portuguese population of the Tolerance for Infidelity Scale showed two dimensions: tolerance for sexual infidelity and tolerance for emotional infidelity. Both dimensions revealed good internal consistency: respectively, $\alpha=0,896 ; \alpha=0,878$. The tolerance for sexual infidelity presented good temporal stability and the tolerance for emotional infidelity very good temporal stability. Gender differences were not found regarding these dimensions. Participants who were married or were in a civil union scored higher in tolerance for sexual infidelity, in contrast with participants that were single, widows, were separated and divorced. Participants who reported having forgiven a situation of infidelity presented higher tolerance for sexual infidelity, than those who did not. Also, participants that expressed not having difficulty in forgiving, presented higher tolerance for both types of infidelity, in comparison to who expressed difficulty in forgiving. Conclusions: The adapted version of the Tolerance for Infidelity Scale showed good internal consistency (total and subscales) and good temporal stability. The associations with marital status and with variables about forgiveness regarding infidelity seem to point out to the validity of the scale, but more studies are needed that explore, namely, the scale construct validity. 


\section{INTRODUÇÃO}

Existe ainda pouco consenso quanto à definição de infidelidade (Blow e Harnett, 2005). Segundo Drigotas e Barta (2001), a infidelidade caracteriza-se pela rutura de regras estabelecidas com o parceiro ao nível da intimidade emocional e física. Assim, a relação monogâmica é definida pelo estabelecimento de que a intimidade emocional e física apenas é aceitável entre as pessoas envolvidas na relação (Luo, Carton e Snider, 2010), havendo, assim, exclusividade para com o parceiro da relação primária (Treas e Giesen, 2000). A quebra desta regra resulta na perda de confiança por parte do parceiro que foi traído e na instabilidade relacional/conjugal (Fife, Weeks e Stellberg-Filbert, 2013). Vários estudos mostram taxas elevadas de prevalência de infidelidade. Em casais americanos, entre $20-40 \%$ dos homens casados e $20 \%-25 \%$ das mulheres casadas terão um envolvimento extraconjugal em toda a vida (e.g. Laumann et al., 1994, citado por Tsapelas, Fisher, e Aron, 2010; Tafoya e Spitzberg, 2007, citado por Tsapelas et al., 2010). No estudo de Allen e Baucom (2006) foi encontrada uma taxa de incidência de infidelidade de $70 \%$ em casais que estejam a namorar. No estudo Português de Martins (2012), 22,8\% e $29,1 \%$, respetivamente, das mulheres e dos homens referiram ter sido infiéis.

De acordo com Glass e Wright (1992, citado por Martins, 2012) existem dois tipos de infidelidade: emocional (vínculo emocional e de afeto com outra pessoa através do flirting, intimidade e enamoramento) e sexual (envolvimento sexual com outro parceiro fora do relacionamento primário, e/ou a possibilidade de contacto). Drigotas, Saftstrom e Gentilia (1999) salientam diversos motivos para a infidelidade como a insatisfação na relação, o interesse sexual, o contexto social, a vingança-hostilidade, entre outros. No estudo de Martins (2012) os motivos apontados para a infidelidade foram o sentido de oportunidade e o aborrecimento na relação (nos homens) e a infelicidade na relação (nas mulheres). Foram, porém, apontados outros motivos como a infidelidade do parceiro, a falta de atração pelo parceiro, desinteresse sexual ou falta de sexo e vontade de terminar a relação, em ambos os sexos (Martins, 2012). Vários estudos (Atkins, Baucom e Jacobson, 2001; Buss e Shackelford, 1997; Shackerford, Besser e Goetz, 2008) mostraram que níveis mais baixos de satisfação conjugal (em ambos os sexos) aumentam a probabilidade de envolvimento extraconjugal. Mark, Janseen e Milhausen (2009) encontraram uma relação entre níveis mais baixos de felicidade, satisfação e compatibilidade sexual e infidelidade.

Alguns estudos debruçaram-se sobre as diferenças de sexo no que toca à infidelidade. Atkins (2001) salientou uma maior probabilidade das mulheres se envolverem emocionalmente, fora da relação, do que em termos físicos e/sexuais (ao contrário dos homens que se envolvem com maior frequência sexualmente). Numa metanálise (1983) relativa a estudos sobre infidelidade em casais americanos que se encontravam casados, Thompson concluiu que $31,0 \%$ dos homens e $16 \%$ das mulheres tinham tido um envolvimento extraconjugal (sexual), sem que existisse envolvimento emocional e que $13 \%$ dos homens e $21 \%$ das mulheres tinham estado envolvidas emocionalmente (mas não sexualmente) com alguém que não o seu parceiro.

Apesar de, como referido, a prevalência e incidência das situações de infidelidade serem elevadas (independentemente das diferenças por sexo), estas situações são bastante penalizadas na cultura ocidental. Um estudo realizado nos Estados Unidos da América (Smith, 1994, citado por Treas e Giesen, 2000) mostrou que $90 \%$ dos americanos desaprovavam sempre ou quase sempre, do ponto de vista moral, o envolvimento extraconjugal. Laumann e colaboradores (1994, citado por Tsapelas et al., 2010) numa amostra próxima dos 3500 americanos relataram que $77 \%$ dos participantes consideravam que o envolvimento sexual fora da relação estava sempre errado. A verdade é que uma situação de infidelidade pode gerar (e gera a maioria das vezes) sentimentos de depressão, raiva e inveja na pessoa traída (Buss, 2000, citado por Tsapelas et al., 2010; Shackelford, LeBlanc, e Drass, 2000) e a infidelidade/traição é apontada em diferentes estudos como devastadora para os casais (Whisman, Dixon, e Johnson, 1997) e como causa para o fim dos relacionamentos (Hall e Fincham, 2006). Betzig (1989, citado por Shackelford, Buss e Bennett, 2002) verificou, no seu estudo, que a infidelidade era a razão mais referida para o divórcio. Flanignan (2007) encontrou uma relação entre traição e término da relação. Mostrou, também, existir maior probabilidade de sair do relacionamento quando se é traído(a) do que quando se trai, havendo ainda maior tendência a sair da relação quando ambos os parceiros traem e/ou são traídos.

Porém, nem todas as pessoas/casais, perante uma situação de infidelidade, abandonam a relação ou optam pelo divórcio. Estudos mostram que, mesmo perante uma situação de infidelidade, uma percentagem marcada de casais inicia terapia para procurar "trabalhar" a relação (Glass e Wright, 1988, citado por Lavelle, 2013) e diferentes estudos apontam para resultados favoráveis na manutenção da relação, quando os casais procuram terapia tendo acontecido uma situação de traição (Atkins, Marín, Lo, Klann e Hahlweg, 2010). Neste contexto, dada a prevalência das situações de infidelidade e porque nem 
sempre estas resultam no fim da relação, importa considerar o construto de tolerância à infidelidade e as variáveis que se sabe já estarem associadas ao mesmo. Lavelle (2013) define esta tolerância, precisamente, como dizendo respeito ao facto da pessoa que foi traída permanecer na relação após a traição. Dois fatores parecem ser centrais para a decisão de perdoar (de tolerar a traição e permanecer na relação) ou de terminar a relação, isto de uma forma geral, sem atentar nas diferenças por sexo: a forma como a traição foi descoberta (se aquele que traiu contar que o fez o impacto é menor) e o facto da pessoa que traiu estar disposta ou não a esforçar-se pela relação e a comprometer-se, de novo, com um comportamento monogâmico (o esforço e compromisso associam-se a um menor impacto da traição) (Afifi, Falato e Weiner, 2001; Diblasio, 2000). Shackelford (1997) refere, igualmente, a importância do/a grau/natureza da infidelidade, sendo maior a probabilidade da relação terminar quando a natureza da infidelidade (a sua gravidade) é maior, envolvendo mais custos (para aquele que foi traído e para o casal). E se estes fatores gerais parecem estar associados a uma menor ou maior tolerância à infidelidade, cada vez mais tem surgido interesse em explorar as diferenças de sexo a este nível. Estas diferenças têm sido debatidas, inclusive, tendo em conta a teoria evolucionária proposta por Buss, Larsen, Westen e Semmelroth (1992), sobre a qual nos debruçaremos mais à frente.

Assim, no que diz respeito às diferenças por sexo quanto à tolerância à infidelidade, Lavelle (2013) verificou existir maior probabilidade das mulheres apresentarem níveis menores de tolerância à infidelidade emocional do que os homens, optando por sair da relação, e maior probabilidade de permanecerem na relação, após uma traição, se estiverem casadas. Já os homens revelam maior tolerância à infidelidade emocional e menor tolerância à infidelidade sexual do que as mulheres (Lavelle, 2013). Shackelford e Buss (1997) verificaram que os homens menos satisfeitos no seu relacionamento tinham maior tendência para pedir o divórcio caso a sua parceira beijasse outro homem, tivesse um encontro romântico e uma noite de sexo casual (natureza mais sexual da infidelidade). Em relação às mulheres, apesar de termos visto que estas parecem tolerar melhor a infidelidade sexual, na presença de níveis elevados de conflito, é mais provável que estas saiam da relação se o parceiro tiver tido sexo casual ou um envolvimento de curta duração. 0 estudo de Hall e Fincham (2006) mostrou que os dois tipos de traição resultam mais na dissolução da relação do que a traição emocional isoladamente. No estudo de Shackelford, Buss e Bennett (2002), no caso de ambos os parceiros terem traído, o risco de terminar a relação existindo envolvimento sexual e emocional foi maior nos homens do que nas mulheres. Igualmente, cerca de $61,9 \%$ dos homens e $22,0 \%$ das mulheres ficaram mais incomodados quando existiu envolvimento sexual (versus envolvimento emocional). Shackelford, Buss e Bennett (2002) confirmaram o mesmo, verificando que os homens consideram ser mais difícil perdoar a infidelidade sexual em comparação com as mulheres. Já as mulheres consideram ser mais fácil perdoar a infidelidade sexual e mais difícil perdoar a infidelidade emocional. Harris (2003) numa amostra de mulheres estudantes universitárias verificou que os homens têm ciúmes em relação à infidelidade sexual e as mulheres à infidelidade emocional. Amato e Previti (2003) estudaram o perdão após o divórcio, verificando que os homens têm mais dificuldade em perdoar a infidelidade sexual. Outros estudos (Amato e Previti, 2003; Urooj, Haque e Anjum, 2015) confirmam que os homens têm dificuldade em perdoar a infidelidade sexual e que as mulheres têm dificuldades em perdoar os dois tipos de infidelidade, mas sobretudo a emocional. Não podemos deixar de referir o que Blow e Harnnett (2005) definem como pressão cultural para as mulheres tolerarem a infidelidade, de forma a preservarem o casamento e a manterem a família unida. Também Flanigan (2007) refere o papel da socialização no que toca à prestação de cuidados, assertividade e empatia, o que pode originar uma maior probabilidade das mulheres perdoarem a infidelidade do parceiro.

Como já referido previamente, as diferenças encontradas empiricamente ao nível da tolerância face à infidelidade por sexo são explicadas, a um nível teórico, maioritariamente, pela perspetiva evolucionária, que foca a natureza da infidelidade (e.g. Buss et al., 1992). Assim, se considerarmos os nossos antepassados, ao ocorrer uma única situação de infidelidade sexual por parte da mulher, tal pode colocar em causa a certeza de paternidade, no caso do homem (não se colocando dúvidas quanto à maternidade), podendo levá-lo a investir esforço num filho de um outro homem e não seu. Este facto aumenta a probabilidade dos homens apresentarem maior ciúme e sofrimento e menor tolerância à infidelidade sexual do que à emocional. Já no caso das mulheres, uma circunstância única de infidelidade pelo parceiro, não comporta tanto risco, até porque o esforço da mulher continua a existir face a um filho que tem a certeza de ser geneticamente seu. Porém, se o seu parceiro ficar envolvido emocionalmente com outra mulher, tal pode diminuir os esforços, compromisso e investimento do parceiro em si e no(s) filho(s), envolvendo mais custos do ponto de vista evolucionário (Buss et al., 1992).

E se existem vários estudos a debruçarem-se sobre as diferenças na tolerância à infidelidade por sexo, alguns estudos consideraram a associação de outras variáveis (de 
natureza intra e interpessoal) com este construto, embora a maioria dos estudos que se dedicam a explorar correlatos na área da infidelidade, fazem-no, realmente, com o construto de infidelidade e não com o de tolerância à infidelidade (e.g. revisão de Blow e Hartnett, 2005). No estudo de Lavelle (2013) os sujeitos que melhor mostraram tolerar a infidelidade emocional foram aqueles com baixos níveis de ciúme e com uma dependência "saudável" ou os que apresentavam uma vinculação insegura evitante. Os mais tolerantes à infidelidade sexual possuíam vinculação insegura ansiosa e evitante e níveis disfuncionais de dependência. As mulheres foram as que revelaram menor tolerância à infidelidade emocional, para além daqueles que, independentemente do sexo, apresentavam níveis elevados de ciúme. Miller e Manner (2009) também enfatizaram o papel moderador da variável ciúme crónico nas respostas face à infidelidade por sexo. Assim, se os homens apresentaram níveis maiores de "ciúme sexual" do que as mulheres, as diferenças de sexo no que toca a este "ciúme" foram claramente moderadas pelo facto do sujeito apresentar ou não ciúme crónico. Bornstein (2006) menciona a dependência emocional ou financeira como um importante fator que reduz a probabilidade da pessoa deixar a relação na presença de uma traição. Poortman e Seltzer (2007) referem, igualmente, o medo e/ou expectativa de, quando existem filhos, terminar a relação numa situação de traição, possa condicionar a capacidade de responder às necessidades socioemocionais dos filhos. Shackelford (1997) refere, também, o papel que níveis menores de satisfação na relação terão na dissolução da relação, face à infidelidade do(a) parceiro(a). Cann e Baucom (2004) e Finkel, Rusbult, Kumashiro, e Hannon (2002) apontam um maior sentimento de compromisso como aumentando a probabilidade de se aceitar perdoar algumas transgressões por parte do parceiro (mesmo que este sentimento também vá originar maior sofrimento, precisamente na presença destas transgressões). Buss (1994, citado por Lavelle, 2013) aponta ainda a crença de se poder vir a encontrar (ou não) um novo parceiro melhor do que atual, numa situação de infidelidade, como condicionando a decisão de se manter ou não na relação, após uma situação desse tipo.

Dado que o construto de tolerância à infidelidade tem sido menos estudado que o de infidelidade, não temos conhecimento de algum estudo que tenha explorado a associação entre a tolerância à infidelidade e constructos derivados da teoria das mentalidades sociais, como o autocriticismo e a autocompaixão. A teoria das mentalidades sociais parte de uma perspetiva evolucionária (Gilbert, 2005) e refere o autocriticismo como uma relação eu-eu, na qual os indivíduos adotam uma postura crítica e punitiva face aos seus erros e fracassos, e que tem a sua base nas experiências precoces com as figuras de vinculação (Castilho, Gouveia e Amaral, 2010; Gilbert, Clarke, Hempel, Miles e Irons, 2004; Gilbert, Clark, Hempel, Miles e Irons, 2004). Já a compaixão envolve não só a consciência, mas a abertura calorosa e desejo de aliviar o sofrimento dos outros e do eu, reconhecendo que a inadequação e/ou o fracasso fazem parte da experiência humana universal. Assim, Neff (2003a; 2003b) definiu a autocompaixão como uma atitude calorosa e de aceitação pelos aspetos negativos do eu ou da vida em geral, sendo constituída por três componentes básicos: calor/compreensão (versus julgamento), condição humana (versus isolamento) e mindfulness (versus sobreidentificação). A autocompaixão pode, então, ser uma estratégia de regulação emocional, já que envolve compreender que os erros, fracassos e inadequações fazem parte da condição humana (Neff, 2003a). Estudos mostram que pessoas mais autocompassivas são mais empáticas, mais capazes de apresentar compaixão relativamente ao outro (Neff e Pommier, 2013) e menos críticas perante os momentos difíceis, erros ou falhas dos outros (Neff, 2003b) (aqui podemos pensar, por exemplo, numa situação de infidelidade), enquanto que pessoas mais autocríticas são tendencialmente mais críticas com o outro (Zuroff, Moskowitz e Côté, 1999) e tendem a criticar mais os seus erros, falhas e fracassos (Thompson e Zuroff, 2004).

No que toca à área da infidelidade e ao seu estudo, como acima mencionado, a maioria dos estudos foca-se no construto de infidelidade que, por si só, já apresenta inconsistências, segundo Blow e Hartnett (2005), explorando muito menos a questão da tolerância à infidelidade. Estes autores acabam por refletir num ponto central, o facto de existir poucos estudos suficientemente rigorosos nesta área, apontando, nomeadamente para os medos associados à confidencialidade e anonimato quando os sujeitos participam em estudos sobre o tema. Igualmente, no que toca aos instrumentos de auto-relato existentes nesta área de investigação, existem alguns que se debruçam sobre as atitudes face à infidelidade (Afonso, 2011), os comportamentos, contextos e motivações associados à infidelidade (Viegas e Moreira, 2015) e as conceções face a infidelidade (Viegas e Moreira, 2013) mas quanto à tolerância à infidelidade, apenas temos conhecimento da existência da Tolerance for Infidelity Scale (Escala de Tolerância à Infidelidade), que foi especificamente criada por Lavelle (2013) para avaliar este construto.

Atendendo aos escassos instrumentos de auto relato e estudos no âmbito da tolerância à infidelidade, particularmente no nosso país, mas também ao nível internacional, são nossos objectivos centrais: adaptar e validar preliminarmente a versão portuguesa da Escala de Tolerância à Infidelidade (ETI) de Lavelle (2013); explorar associações entre a tolerância à infidelidade e diferentes 
questões sociodemográficas (sexo, idade, estado civil, escolaridade), relacionais (satisfação com a relação atual, no caso de estar numa relação) e relativas à infidelidade e perdão face à mesma (ter traído, saber ter sido traído, ter perdoado, motivos para trair e perdoar, entre outras) e os construtos de autocriticismo e autocompaixão (estas duas, pela forma como, hipoteticamente, pessoas mais autocríticas terão maior dificuldade em tolerar a falha do parceiro/a ao trair e as mais autocompassivas maior facilidade em fazê-lo).

\section{MÉTODO}

\section{Participantes}

A amostra recolhida foi não probabilística por conveniência (Pais-Ribeiro, 2010). Como critérios de inclusão no estudo, os participantes tinham de ter nacionalidade Portuguesa, saber ler e ter uma idade superior a 18 anos.

A amostra ficou constituída por 223 participantes, 155 do sexo feminino (69,5\%) e 68 do sexo masculino (30,5\%), com idades entre os 18 e os 67 anos $(M=32,21$; $D P=11,45)$. Constatou-se que $46,2 \%$ dos participantes possuía uma licenciatura $(n=103)$ e $96 \%$ referiu ser heterossexual $(n=$ 214). Verificou-se, ainda, que $58,3 \%$ dos sujeitos mencionou estar solteiro $(n=130)$ (Tabela 1$)$.

Tabela 1

Caracterização Sociodemográfica da Amostra

\begin{tabular}{|c|c|c|c|}
\hline Sexo & & $n$ & $\%$ \\
\hline Feminino & & 155 & 69,5 \\
\hline Masculino & & 68 & 30,5 \\
\hline Total & & 223 & 100,0 \\
\hline \multirow[t]{2}{*}{ Idade } & & $M(D P)$ & Intervalo \\
\hline & & $32,31(11,45)$ & $18-67$ \\
\hline Escolaridade & & $n$ & $\%$ \\
\hline $1^{\circ}-2^{\circ} \mathrm{Ciclo}$ & & 2 & 0,8 \\
\hline $3^{\circ} \mathrm{Ciclo}$ & & 5 & 2,2 \\
\hline Ensino Secundário & & 72 & 32,3 \\
\hline Curso Profissional & & 19 & 8,5 \\
\hline Licenciatura & & 103 & 46,2 \\
\hline Mestrado & & 18 & 8,1 \\
\hline \multirow[t]{2}{*}{ Doutoramento } & & 4 & 1,8 \\
\hline & Total & 223 & 100,0 \\
\hline Orientação Sexual & & $n$ & $\%$ \\
\hline Heterossexual & & 214 & 96,0 \\
\hline Homossexual & & 3 & 1,3 \\
\hline Bissexual & & 5 & 2,4 \\
\hline Pansexual & & 1 & 0,4 \\
\hline Total & & 223 & 100,0 \\
\hline Estado civil & & $n$ & $\%$ \\
\hline Solteiro(a) & & 130 & 58,3 \\
\hline União de Facto & & 30 & 13,5 \\
\hline Casado(a) & & 43 & 19,3 \\
\hline Viúvo(a) & & 2 & 0,9 \\
\hline Separado(a) & & 2 & 0,9 \\
\hline \multirow[t]{2}{*}{ Divorciado(a) } & & 16 & 7,2 \\
\hline & Total & 223 & 100,0 \\
\hline
\end{tabular}

Notas: $n=$ frequência; \% = percentagem; $M=$ Média; $D P$ = Desvio-padrão.
Nas Tabelas 2 e 3 são apresentados dados relacionais e sobre infidelidade. A maioria dos sujeitos referiu estar num relacionamento/casamento ( $n=169 ; 75,8 \%)$, com uma duração média de 84,09 meses $(D P=100,87)$ (cerca de 7 anos), estando extremamente satisfeito com o mesmo ( $n$ $=44 ; 26,0 \%$ ).

A maioria referiu nunca ter traído ( $n=165 ; 74,0 \%$ e entre os que traíram, a maioria referiu ter-se arrependido ( $n=17 ; 35,4 \%$ ) (porém, a mesma percentagem de pessoas não respondeu a esta questão) e ter contado ao seu/sua companheiro/a ou marido/esposa ( $n=17 ; 35,4 \%)$.

O motivo mais referido para a traição foi a saturação com a relação atual $(n=11 ; 22,9 \%)$.

Também a maioria confessou saber ter sido alguma vez traído ( $n=90 ; 40,4 \%)$ e dos que souberam ter sido traídos, a maioria não perdoou o/a companheiro/a $(n=56$; $25,1 \%)$.

Entre os que perdoaram, a maioria referiu ter sido difícil fazê-lo ( $n=28 ; 77,8 \%)$, sendo o motivo mais referido o amor $(n=12 ; 33,3 \%)$.

A maioria dos participantes respondeu que os pais não eram divorciados/separados ( $n=163 ; 73,1 \%$ ), mas entre aqueles que responderam que sim, a maioria referiu que o divórcio/separação se associou a uma situação de traição $(n=22 ; 36,7 \%)$.

Tabela 2

Dados Relacionais e Sobre Infidelidade (e Perdão Face à Mesma)

\begin{tabular}{|c|c|c|}
\hline Num relacionamento/casamento (atualmente) & $n$ & $\%$ \\
\hline Sim & 169 & 75,8 \\
\hline \multirow[t]{2}{*}{ Não } & 54 & 24,2 \\
\hline & 223 & 100,0 \\
\hline \multirow[t]{2}{*}{ Tempo de duração da relação } & $M(D P)$ & Intervalo \\
\hline & $84,09(100,87)$ & $0-502$ \\
\hline Satisfação com o relacionamento atual & $n$ & $\%$ \\
\hline 1 Nada Satisfeito(a) & 2 & 1,2 \\
\hline 2 & 3 & 1,8 \\
\hline 3 & 18 & 10,7 \\
\hline 4 & 32 & 18,9 \\
\hline 5 & 28 & 16,6 \\
\hline 6 & 49 & 23,1 \\
\hline 7 Extremamente Satisfeito(a) & 44 & 26,0 \\
\hline Total & 166 & 98,2 \\
\hline Alguma vez traiu & $\mathbf{n}$ & $\%$ \\
\hline $\operatorname{Sim}$ & 48 & 21,5 \\
\hline Não & 165 & 74,0 \\
\hline Quis trair, mas não o fiz & 9 & 4 \\
\hline Total & 222 & 99,6 \\
\hline Arrependimento em relação à traição & $n$ & $\%$ \\
\hline $\operatorname{Sim}$ & 17 & 35,4 \\
\hline Não & 13 & 27,1 \\
\hline \multirow[t]{2}{*}{ Não se aplica } & 18 & 37,5 \\
\hline & 48 & 100,0 \\
\hline
\end{tabular}

Notas: $n$ = frequência; \% = percentagem; $M$ = Média; $D P$ = Desvio-padrão. 
Tabela 3

Dados Relacionais e Sobre Infidelidade (e Perdão Face à Mesma)

\begin{tabular}{|c|c|c|c|}
\hline Contou ao companheiro(a)/marido/esposa & & $\mathbf{n}$ & $\%$ \\
\hline $\operatorname{Sim}$ & & 17 & 35,4 \\
\hline Não & & 15 & 31,3 \\
\hline \multirow[t]{2}{*}{ Não se aplica } & & 16 & 33,3 \\
\hline & Total & 48 & 100,0 \\
\hline Motivos para a traição & & $\mathbf{n}$ & $\%$ \\
\hline Apaixonei-me por outra pessoa & & 10 & 20,8 \\
\hline Saturação com a relação atual & & 11 & 22,9 \\
\hline Tempo curto da relação & & 5 & 10,4 \\
\hline Tempo longo da relação & & 2 & 4,2 \\
\hline \multirow[t]{2}{*}{ Não se aplica } & & 19 & 39,6 \\
\hline & Total & 47 & 97,9 \\
\hline Dependência emocional/afectiva & & 10 & 27,8 \\
\hline Tempo longo da duração & & 1 & 2,8 \\
\hline Amor + pelo medo de ser julgado & & 1 & 2,8 \\
\hline Amor + dependência emocional & & 5 & 13,9 \\
\hline Amor + pelos filhos & & 1 & 2,8 \\
\hline Amor + tempo longo da relação & & 3 & 8,3 \\
\hline Amor+ pelos filhos + tempo longo da relação & & 1 & 2,8 \\
\hline \multirow[t]{2}{*}{ Não se aplica } & & 2 & 5,6 \\
\hline & Total & 36 & 100,0 \\
\hline Foi difícil perdoar & & n & $\%$ \\
\hline Sim & & 28 & 77,8 \\
\hline \multirow[t]{2}{*}{ Não } & & 8 & 22,2 \\
\hline & Total & 36 & 100,0 \\
\hline Os pais são divorciados/separados & & n & $\%$ \\
\hline $\operatorname{Sim}$ & & 60 & 26,9 \\
\hline \multirow[t]{2}{*}{ Não } & & 163 & 73,1 \\
\hline & Total & 233 & 100,0 \\
\hline Motivo da separação dos pais foi a traição & & $n$ & $\%$ \\
\hline Sim & & 22 & 36,7 \\
\hline \multirow[t]{2}{*}{ Não } & & 20 & 33,3 \\
\hline & Total & 42 & 70,0 \\
\hline
\end{tabular}

\section{Procedimentos}

Após a definição do protocolo de investigação foram enviados pedidos de autorização aos autores para a utilização dos instrumentos. Foi desenvolvido um questionário sociodemográfico, relacional e com questões acerca da infidelidade e tolerância à infidelidade (e.g. perdão, motivos para perdoar). De seguida, após as autorizações serem concedidas e após a autora da escala (Lavelle, 2013) ter facultado o instrumento, procedeu-se à adaptação da Escala de Tolerância à Infidelidade (ETI), com as autoras do trabalho a traduzirem-na para a língua portuguesa. Seguiu-se a sua retroversão, realizada, igualmente, pelas autoras do trabalho e confirmada por uma investigadora da Universidade de Coimbra (todas fluentes em inglês). Recorreu-se ao método da reflexão falada, que consiste na aplicação individual do instrumento junto de sujeitos próximos dos futuros destinatários do mesmo e no registo de todas as suas verbalizações (estes devem comunicar as suas impressões sobre os itens, nomeadamente os processos utilizados e as facilidades ou dificuldades que tiveram ao responder-
Ihes) (Goldman, 1971, citado por Almeida e Freire, 2008). Assim, junto de cinco jovens adultos recolheu-lhe feedback sobre o conteúdo e entendimento dos itens que compunham a ETI. Procedeu-se a alterações minor ao nível do conteúdo de alguns itens da ETI. Deu-se início, posteriormente, à recolha dos dados do presente estudo, que decorreu entre março a junho de 2016. As autoras pretendiam, à data de início de recolha dos dados, um número mínimo de 120 participantes (10 sujeitos por cada item da ETI), seguindo o critério mínimo de Kerlinger (1986). O estudo foi divulgado através de redes sociais (Facebook), onde se solicitou aos participantes que preenchessem o protocolo online (composto por vários instrumentos, para além da ETI: questionário sociodemográfico, relacional e relativo à infidelidade e tolerância à infidelidade), recorrendo à plataforma Google Docs. Antes do preenchimento, nessa mesma plataforma, seguindo imperativos éticos, as autoras incluíram um texto descritivo sobre os objectivos, os critérios de inclusão no estudo e confidencialidade dos dados a serem recolhidos. Foi obtido o consentimento informado de todos os participantes (que tiveram de assinalar "consinto participar no presente estudo"). Para testar a estabilidade temporal da ETI, a escala foi preenchida, em dois momentos, por 29 adultos. Neste caso, foram contactados sujeitos próximos das investigadoras e solicitada a sua participação, para evitar a ausência de resposta no segundo momento. Foi explicada a necessidade de preenchimento do mesmo instrumento em dois momentos distintos e assegurada a confidencialidade dos dados recolhidos. No primeiro momento, a ETI foi entregue a cada um dos sujeitos que concordou participar, dando o seu consentimento informado. No topo direito da folha onde a ETI estava impressa, constava um número. Pediu-se aos participantes que o decorassem. Não foram recolhidos quaisquer dados sociodemográficos (ou de outra natureza) e a estes sujeitos apenas se pediu participação no preenchimento da ETI (não se solicitou o preenchimento do protocolo completo). Num segundo momento (reteste), passadas quatro semanas, foi entregue aos participantes, de novo, a ETI (com uma linha no topo direito da folha para os sujeitos escreverem o número que lhe tinha sido atribuído na primeira administração) para a preencherem mais uma vez.

\section{Instrumentos}

Questionário sociodemográfico, relacional e relativo à infidelidade (e ao perdão face à mesma). Este questionário apresentou questões sobre informação sociodemográfica (sexo, idade, escolaridade, orientação sexual e estado civil), relacional (frequência, durabilidade e satisfação com o relacionamento/casamento) e relativa à infidelidade e perdão face à mesma (ter traído/ter sido traído(a), 
contado ao companheiro(a), motivos para ter traído e para perdoar e grau de dificuldade em perdoar, separação/divórcio dos pais ser devido a uma traição).

\section{Escala de Tolerância à Infidelidade (Infidelity} Tolerance Scale/ITS, Lavelle, 2013). A ETI avalia a permanência ou saída do parceiro(a) da relação amorosa após uma traição (Lavelle, 2013). Possui 12 itens que descrevem diferentes formas pelas quais o parceiro pode trair, avaliando-se a probabilidade do respondente permanecer na relação, conforme essas possíveis formas de traição, pelo parceiro. As respostas são dadas numa escala de Likert entre 1 (extremamente provável deixar a relação) a 7 (extremamente provável permanecer na relação), oscilando a pontuação mínima e máxima na escala entre 12 e 84, com uma pontuação maior (na escala total e subescalas) a indicar uma maior tolerância à infidelidade. A ETI na sua versão original apresentou duas subescalas (tolerância à traição emocional e tolerância à traição sexual) e demonstrou uma boa consistência interna (escala total: $\alpha=0,87$; tolerância à infidelidade sexual: $\alpha=0,78$; tolerância à infidelidade emocional: $\alpha=$ 0,73.) (Lavelle, 2013). No Quadro 1 apresentamos os itens da versão original da ETI e os itens traduzidos da versão portuguesa.

\section{Quadro 1}

Itens da Versão Original da Escala de Tolerância à infidelidade e Tradução dos Mesmos

\begin{tabular}{ll}
\hline \multicolumn{1}{c}{ Itens da versão original } & \multicolumn{1}{c}{ Itens traduzidos da versão portuguesa } \\
\hline $\begin{array}{ll}\text { 1. I was in a new relationship with someone I really loved and they confessed to } \\
\text { having a one night stand. }\end{array}$ & $\begin{array}{l}\text { 1. Estivesse numa relação recente com alguém que eu realmente amasse e essa } \\
\text { pessoa confessasse ter tido sexo casual/ido para a cama com outra pessoa. }\end{array}$ \\
\hline $\begin{array}{l}\text { 2. I was in a long-term relationship, and my partner admitted to having feelings } \\
\text { for a co-worker. }\end{array}$ & $\begin{array}{l}\text { 2. Estivesse numa relação de longa duração e o meu parceiro(a) admitisse ter } \\
\text { sentimentos por um(a) colega. }\end{array}$
\end{tabular}

3. We were married and had kids, and my partner admitted to cheating once.

3. Estivéssemos casados e tivéssemos filhos e o(a) meu/minha marido/esposa admitisse ter-me traído uma vez.

4. I was engaged and my partner confessed to having an ongoing affair earlier in the relationship.

4. Estivesse noivo(a) e o meu parceiro(a) admitisse ter tido um caso no início do relacionamento.

5. My husband/wife admitted to kissing someone else on one occasion, but did not engage in sexual intercourse with that person.

6. We were married and had kids, and my partner admitted to being in love with another person with whom s/he did not have any physical contact.

7. I was in a long-term relationship and my partner was having an ongoing affair, but promised to end it immediately and work on the relationship.

8. My husband/wife cheated once and we were about to have our first child.
5. O(a) meu/minha marido/esposa admitisse ter beijado alguém numa ocasião, mas sem ter tido relações sexuais com essa pessoa.

6. Estivéssemos casados e tivéssemos filhos e o(a) meu/minha marido/esposa admitisse ter-se apaixonado por outra pessoa com a qual não teve qualquer contato físico.

7. Estivesse numa relação de longa duração e o(a) meu/minha parceiro(a) estivesse a ter um caso, mas prometesse terminá-lo imediatamente e melhorar a nossa relação.

8. O(a) meu/minha marido/esposa me traísse uma vez e estivéssemos prestes a ter o primeiro filho(a).
9. I was married and in love with my partner, and they continued to have meaningless casual sex with other people.

10. The person I was dating admitted to kissing another person with whom they felt a connection, but did not engage in sexual intercourse.

11. My husband or wife was in love with another person who was married, but they never engaged in sexual behavior.
9. Estivesse casado(a) e apaixonado(a) pelo(a) meu/minha marido/esposa e ele(a) continuasse a ter sexo casual sem significado com outra(s) pessoa(s).
12. My boyfriend/girlfriend admitted that they would rather be with another person, had the other person been interested.
10. A pessoa com quem estivesse a sair admitisse ter beijado outra pessoa com quem sentiu uma ligação, mas sem nunca se terem envolvido sexualmente.

11. O(a) meu/minha marido/esposa estivesse apaixonado(a) por outra pessoa casada, mas sem nunca se terem envolvido sexualmente pessoa, caso a outra pessoa estivesse interessado(a).

Escala das Formas do Autocriticismo $e$ de Autotranquilização (FSCRS, Forms of SelfCritizing/Attacking and Self-Reassuring Scale; Gilbert, Clarke, Hempel e Irons, 2004; Castilho e Pinto Gouveia, 2011a). A FSCRS avalia a forma como os indivíduos se autocriticam e autotranquilizam em situações de fracasso, falha e ineficácia pessoal (Castilho e Pinto Gouveia, 2011a). Possui 22 questões respondidas numa escala de Likert de 0 (não sou assim) a 4 (sou extremamente assim), e divididas em três subescalas: eu inadequado ( 9 itens; avalia os sentimentos de inadequação e inferioridade do indivíduo perante o fracasso, obstáculos e erros); eu tranquilizador 
(8 itens; face a um erro adota um comportamento mais positivo e de compaixão) e eu detestado ( 5 itens; avalia um sentimento de repugnância/ódio e perseguição do próprio eu). A pontuação de autocriticismo é calculada somando os itens relativos ao eu inadequado e eu detestado (esta pontuação pode oscilar entre o e 56), com um pontuação mais elevada a indicar um maior grau de autocriticismo. Na versão original, obtiveram-se os seguintes valores de alfa de Cronbach: 0,90, 0,86 e 0,86 respetivamente, no eu inadequado, eu detestado e eu tranquilizador (Gilbert et al., 2004). A versão portuguesa (Castilho e Pinto Gouveia, 2011a) apresenta uma consistência interna muito boa. Os valores de alfa de Cronbach foram de 0,89 (eu inadequado), 0,62 (eu detestado) e 0,87 (eu tranquilizador). O presente estudo apresentou valores alfa de Cronbach de 0,88, 0,75 e 0,89, respetivamente, nessas subescalas (entre razoáveis e bons, Pestana e Gageiro, 2008).

Escala de Autocompaixão (SELFCS, Self-Compassion Scale, Neff, 2003a; Castilho e Pinto Gouveia, 2011b). A SELFCS permite avaliar a autocompaixão, que diz respeito à capacidade de estar aberto ao próprio sofrimento, com sentimentos de calor, cuidado e compreensão para com o eu (Neff, 2003a). Segundo esta autora, a autocompaixão inclui três componentes que são avaliados pela SELFCS: calor/compreensão versus autocrítica; condição humana versus isolamento e mindfulness versus sobreidentificação (Castilho et al., 2011b). Possui 26 itens de resposta, respondidos numa escala de Likert entre 1 (quase nunca) a 5 (quase sempre) (Castilho et al., 2011b) e divide-se em 6 subescalas: calor/compreensão ( 5 itens) versus autocrítica ( 5 itens); condição humana (4 itens) versus isolamento (4 itens) e mindfulness ( 4 itens) versus sobreidentificação (4 itens) (Castilho et al., 2011b). No estudo original revelou boa consistência interna nas subescalas: calor/compreensão ( $\alpha=0,78)$, autocrítica $(\alpha=0,77)$, condição humana $(\alpha=0,80)$, isolamento $(\alpha=0,70)$, mindfulness $(\alpha=0,75)$ e sobreidentificação $(\alpha=0,81)$ (Neff, 2003a). Em relação à cotação da escala, esta pode ser cotada de forma geral ou pelas subescalas. O cálculo é efetuado através da média dos itens que constituem a subescala/escala total, recorrendo à inversão dos itens 1, 2, 4, 6, 8, 11, 13, 16, 18, 20, 21, 24 e 25 (Neff, 2003a). A cotação final pode ser classificada da seguinte forma: baixa autocompaixão (intervalo de 1 a 2,5), moderada autocompaixão (intervalo de 2,5 a 3,5) e elevada compaixão ( 3,5 a 5). A versão portuguesa revelou uma boa consistência interna, com os seguintes valores: de 0,84 (calor/compreensão), 0,82 (autocrítica), 0,77 (condição humana), 0,75 (isolamento), 0,73 (mindfulness) e 0,68 (sobreidentificação) (Castilho et al., 2011b). No presente estudo obtivemos alfas de Cronbach, respectivamente, nas mesmas escalas de: $0,84,0,80,0,68,0,78,0,72$ e 0,78 (valores razoáveis e bons, na sua maioria, de acordo com Pestana e Gageiro, 2008).

\section{Análise estatística}

Os dados foram analisados através do Statistical Package for the Social Sciences (SPSS), versão 19.0. Determinámos estatísticas descritivas, medidas de tendência central, dispersão, assimetria e achatamento.

A consistência interna da ETI foi analisada através do cálculo de alfas de Cronbach. Explorou-se a validade interna de cada item analisando as correlações entre cada item e o total corrigido (excluindo o item) e pelos coeficientes $\alpha$ excluindo um a um os itens.

Realizou-se uma análise de componentes principais, seguida de rotação Varimax para componentes com eigenvalues igual ou superiores a 1 (seguindo-se as indicações de Pallant, 2007), sendo usados, para extrair as dimensões/os fatores da ETI, o critério de Kaiser (Kaiser, 1970, 1974) e o Teste de Scree de Cattell (Catell, 1966).

A consistência interna das subescalas da ETI foi analisada calculando alfas de Cronbach. Correlações de Pearson permitiram testar a estabilidade testereteste da escala.

Testes $t$ de Student permitiram explorar diferenças por sexo na tolerância à infidelidade. Através de novas correlações de Pearson, exploramos associações entre as dimensões/fatores que emergiram da análise de componentes principais da ETI com as dimensões dos instrumentos FSCRS e SELFCS. Usámos os critérios de Cohen (1992) para classificar a magnitude das correlações. Recorremos a testes $t$ de student, $U$ de Mann Whitney e correlações de Pearson e Spearman (os testes paramétricos e não paramétricos foram utilizados em função do número de participantes por categoria) para testar associações entre as dimensões da ETI e as variáveis sociodemográficas, relacionais e relativas à traição/infidelidade. Foi considerado o nível de significância estatística de $p \leq 0,05$.

\section{RESULTADOS}

\section{Fidelidade}

Consistência interna da escala. Este parâmetro (Tabela 4) foi avaliado calculando o respetivo alfa de Cronbach (considerando, portanto, os doze itens da ETI) e este mostrou ser de $\alpha=0,865$ (bom, de acordo com Pestana e Gageiro, 2008). 
Tabela 4

Correlação Item-Total Corrigido e Alfa Excluindo o Item

\begin{tabular}{|c|c|c|}
\hline Escala de Tolerância à Infidelidade & Correlação Item-Total Corrigido & Alfa excluindo o item \\
\hline 1.... confessasse ter-se envolvido sexualmente... & 0,688 & 0,923 \\
\hline 2. ... admitisse ter sentimentos por um colega... & 0,646 & 0,925 \\
\hline 3. ... casados e tivéssemos filhos... ter-me traído uma vez... & 0,784 & 0,919 \\
\hline 4. .... admitisse ter tido um caso no início do relacionamento... & 0,724 & 0,922 \\
\hline 5.....admitisse ter beijado alguém numa ocasião... & 0,767 & 0,920 \\
\hline 6. ... admitisse ter-se apaixonado por outra pessoa... & 0,708 & 0,923 \\
\hline 8. ... me traísse uma vez e estivéssemos... a ter o primeiro filho... & 0,753 & 0,921 \\
\hline 9. .... marido/esposa... ter sexo casual sem significado com outras pessoas... & 0,612 & 0,926 \\
\hline 10. .... admitisse ter beijado outra pessoa... & 0,690 & 0,923 \\
\hline 11. ... marido/esposa... apaixonado(a) por outra pessoa casada... & 0,713 & 0,922 \\
\hline 12. ... admitisse que preferia estar com outra pessoa... & 0,564 & 0,928 \\
\hline
\end{tabular}

Análise de componentes principais, consistência interna das subescalas e estabilidade temporal. Os valores do teste Kaiser-Meker-Oklin Measure of Sampling Adequacy (KMO) (valor obtido de 0,904; um valor considerado significativo é $\geq 0,6$ ) e Bartlett's Test of Sphericity (valor de $p \leq 0,001$; um valor considerado significativo deve ser $\leq$ $0,05)$ permitiram verificar a adequabilidade dos dados para realizar a análise de componentes principais.

Ao explorar a respetiva tabela e o screeplot de Catell verificamos a presença de 3 fatores que, pelo conteúdo, se tornavam dificilmente interpretáveis. Assim, forçámos a análise a dois fatores.

A análise de componentes principais e o screeplot revelou, então, uma estrutura de 2 fatores que explicaram, respetivamente, $56,4 \%$ e $9,5 \%$ da variância. Na Tabela 5 apresentamos as saturações de cada item nos dois fatores.

Apenas existiu dúvida quanto ao item 5, que pareceu apresentar maior saturação no Fator 1. Porém, dado o seu conteúdo, optamos por considerá-lo como pertencente ao Fator 2. Encontrámos, então, 2 fatores compostos pelos seguintes itens: Fator 1. Tolerância à infidelidade sexual: 1, 3, 4, 7, 8, 9; Fator 2. Tolerância à infidelidade emocional: 2, 5, 6, 10, 11, 12.

\section{Tabela 5}

Saturações dos itens da Escala de Intolerância à Infidelidade por Fator

\begin{tabular}{ccc}
\hline & $\begin{array}{c}\text { Fator 1 } \\
\text { Tolerância à Infidelidade Sexual }\end{array}$ & $\begin{array}{c}\text { Fator } \mathbf{2} \\
\text { Tolerância à Infidelidade Emocional }\end{array}$ \\
\hline Item 1 & 0,807 & 0,196 \\
Item 2 & 0,292 & 0,749 \\
Item 3 & 0,782 & 0,353 \\
Item 4 & 0,812 & 0,235 \\
Item 5 & 0,732 & 0,389 \\
Item 6 & 0,323 & 0,796 \\
Item 7 & 0,711 & 0,321 \\
Item 8 & 0,774 & 0,328 \\
Item 9 & 0,580 & 0,363 \\
Item 10 & 0,504 & 0,557 \\
Item 11 & 0,264 & 0,876 \\
Item 12 & 0,260 & 0,674 \\
\hline
\end{tabular}

Considerando a consistência interna de cada dimensão, a tolerância à infidelidade sexual apresentou um alfa de Cronbach de $a=0,896$ e a tolerância à infidelidade emocional de $a=0,878$ (ambas boas, segundo Pestana e Gageiro, 2008).

$\mathrm{Na}$ Tabela 6 apresentamos as médias e desvios padrão de cada dimensão na $1^{\mathrm{a}}$ administração e reteste. Correlações de Pearson das dimensões entre si indicam correlações de magnitude elevada (Cohen, 1992), abonatórias da estabilidade temporal da ETI (tolerância à infidelidade sexual, $r=0,879$; tolerância à infidelidade emocional, $r=0,940)$. As dimensões correlacionam uma com a outra, com magnitude elevada, na primeira administração $(r=0,723)$ e no reteste $(r=0,734)$.

\section{Tabela 6}

Médias e Desvios Padrão dos Fatores da ETI ( $1^{a}$ Administração e Reteste)

\begin{tabular}{lc}
\hline & M (DP) \\
\hline Tolerância à Infidelidade Sexual (1 ${ }^{\text {a }}$ Administração) & $13,51(7,56)$ \\
Tolerância à Infidelidade Emocional (1 a Administração) & $15,16(7,57)$ \\
Tolerância à Infidelidade Sexual (reteste) & $16,59(9,59)$ \\
Tolerância à Infidelidade Sexual (reteste) & $19,10(9,42)$ \\
\hline
\end{tabular}

Notas: $M=$ Média; $D P=$ Desvio-padrão.

\section{Validade de Construto}

Diferenças por sexo nas dimensões da ETI. Através de testes $t$ de Student exploraram-se diferenças na tolerância à infidelidade emocional e sexual, por sexo. Não foram encontradas diferenças estatisticamente significativas.

Associações entre a tolerância à infidelidade, variáveis sociodemográficas, relacionais e relativas à infidelidade (e perdão face à mesma). Fomos explorar diferenças e associações quanto à tolerância à infidelidade (sexual e emocional) por/com diferentes variáveis sociodemográficas, relacionais e relativas à infidelidade (e perdão face à mesma) e tolerância à infidelidade (através 
de correlações de Pearson e Spearman, testes $t$ de Student e $U$ de Mann Whitney): idade, escolaridade, orientação sexual, estado civil, estar numa relação, satisfação na relação atual, ter ou não traído, motivos para trair, ter contado, saber ter sido traído, ter perdoado ou não, motivos para perdoar, divórcio ou não dos pais e saberem se o motivo para divórcio se devera a traição. Encontraram-se diferenças por estado civil e pelas variáveis "perdoou o(a) companheiro(a)/marido/esposa" e "foi difícil perdoar". Os participantes casados/em união de facto apresentaram pontuações estatisticamente mais elevadas na tolerância à infidelidade sexual $(t=-1,951 ; p$ s0,052; casados/união de facto, $M=14,92, D P=8,54$; solteiros, $M=12,82 ; D P=6,96)$, por oposição com os solteiros, viúvos, separados e divorciados. Quem perdoou a infidelidade mostrou maior tolerância à infidelidade sexual ( $t=-3,017 ; p \leq 0,004 ; \operatorname{sim}, M=15,97$; não, $M=11,02$ ) Quem revelou dificuldade em perdoar apresentou menor tolerância à infidelidade sexual $(U=43,000 ; p \leq 0,009$; sim, $M d=12,0$, não, $M d=25,0)$ e emocional $(U=47,015 ; p$ $\leq 0,015$; sim, $M d=14,00$; não, $M d=20,50$ ), do que quem não revelou dificuldade em perdoar.

Associações entre a tolerância à infidelidade, autocriticismo e autocompaixão. Não tendo encontrado diferenças por sexo nas dimensões de tolerância à infidelidade, na amostra total, realizamos correlações de Pearson entre essas dimensões e as dimensões da FSCRS (eu tranquilizador) e da SELFCS (calor/compreensão; condição humana) que também não revelaram diferenças por sexo (nas outras dimensões destes instrumentos foram encontradas diferenças, que não importam apontar neste trabalho). Não foram encontradas associações estatisticamente significativas.

\section{DISCUSSÃO/CONCLUSÃO}

O presente estudo teve como objetivos adaptar e validar preliminarmente a Escala de Tolerância à Infidelidade (ETI) e explorar associações entre o construto de tolerância à infidelidade, variáveis sociodemográficas, relacionais e relativas à infidelidade e perdão face à mesma e o autocriticismo e a autocompaixão.

Mas antes mesmo de explorarmos os dados relativos à validação preliminar da ETI, importa atentar em alguns dos dados sociodemográficos, relacionais e relativos à traição (e perdão da mesma) encontrados no nosso estudo. Na nossa amostra, o motivo mais referido para trair foi a saturação com a sua relação. Este dado vai ao encontro de vários estudos (Mark, Janseen e Milhausen, 2009; Martins, 2012) que também apontaram como motivo principal para a infidelidade a saturação com a relação. De facto, vários estudos (Atkins, Baucom e Jacobson, 2001; Buss e Shackerford, 1997; Drigotas,
Saftstrom e Gentilia, 1999; Shackerford, Besser e Goetz, 2008) verificaram que quanto maior a insatisfação na relação, maior parece ser a predisposição para a infidelidade (emocional e sexual). Em relação ao arrependimento, a maioria daqueles que traíram ( $n=18$; $36,7 \%$ ) sentiram arrependimento. Numa amostra de 159 participantes do sexo masculino 239 do sexo feminino, a maioria revelou ter-se arrependido da traição (Galperin et al., 2013).

Em relação à traição cometida pelo companheiro(a), $40,4 \%$ dos nossos inquiridos revelaram ter conhecimento do ocorrido. Flanignan (2007) reportou que no seu estudo apenas 6,9\% souberam ser traídos (com idades entre os 15 e os 22 anos), em relações de curta duração. Para além do intervalo etário diferente da nossa amostra, no nosso estudo, a média de duração do relacionamento atual (pelo menos) não pode ser considerada de curta duração. Abarcando a nossa amostra, também, pessoas mais velhas e que na atual relação (e eventualmente também numa/noutras anterior/es), experienciaram já outro grau de compromisso relacional, pode fazer sentido que, face a uma situação de infidelidade, a mesma tenha sido revelada numa maior percentagem.

Apesar dos custos eventualmente envolvidos nessa partilha, dado o maior compromisso relacional (dada a maior duração do relacionamento, existência de filhos, estado civil, entre outras variáveis) e a outras variáveis a ser tidas em conta se se desejar manter, ainda assim, o relacionamento (e.g. a ausência de satisfação na relação atual, a manter-se como está), depois de uma traição, pode fazer sentido uma maior percentagem de revelação. Relativamente aos motivos que levaram os nossos participantes a perdoar a traição, a maioria dos sujeitos que perdoou o seu companheiro(a) referiu tê-lo feito por amor e dependência emocional.

O resultado relativo à dependência emocional vai ao encontro de estudos (Flanignan, 2007; Borsntein, 2006) que salientam níveis maiores de dependência emocional como uma das variáveis que explica uma maior tolerância à infidelidade. $\mathrm{O}$ medo de não voltar a ser amado(a) e de não conseguir cuidar de si mesmo pode, então, influenciar a decisão de tolerar a infidelidade. A resposta de tolerância face a infidelidade centrada na existência de amor pode associar-se, consideramos nós, ao sofrimento vivenciado por aquele(a) que é traído e reforçar a importância que a terapia de casal pode ter nestes casos (particularmente se este sentimento de amor for partilhado pelos dois elementos) (Atkins, Marín, Lo, Klann e Hahlweg, 2010).

O tempo longo da relação também foi apresentado por vários dos participantes (isoladamente ou em simultâneo com o amor e a dependência emocional) como um motivo para tolerar a traição. De novo, o sentimento 
de compromisso presente em relações de maior duração pode explicar este dado, o que vai ao encontro do expresso por Cann e Baucom (2004) e Finkel, Rusbult, Kumashiro, e Hannon (2002).

Partindo, então, para os dados relativos à validação preliminar da ETI, no que diz respeito aos resultados relativos à fidelidade da ETI e validade interna dos itens, os resultados foram muito abonatórios (boa fidelidade e todos os itens considerados como "bons" correlacionando-se com valores superiores a 0,30 com o total. Os dados recolhidos com a presente amostra revelaram adequabilidade para a realização da análise de componentes principais, apontando para duas dimensões, tolerância à infidelidade sexual e emocional, ambas revelando boa consistência interna. Estes dados estão em consonância com os resultados obtidos com a versão original da escala (Lavelle, 2013).

Adicionalmente, a tolerância à infidelidade sexual revelou boa estabilidade temporal e a tolerância à infidelidade emocional muito boa estabilidade temporal. Pensamos que estes bons indicadores de fidelidade e validade apontam para a possibilidade desta primeira adaptação da ETI poder ser usada em estudos futuros que pretendam explorar o construto de tolerância à infidelidade, embora sejam necessários mais estudos com amostras mais representativas e que explorem, por exemplo, a validade de construto (nomeadamente a validade convergente e divergente) mais detalhadamente. Os dados aqui apresentados parecem ser um importante contributo na área de estudo da infidelidade (e tolerância à infidelidade), particularmente quando são escassos os instrumentos de avaliação existentes no nosso país nesta área.

Ao explorarmos a validade de construto da ETI e partindo, inclusive, da perspetiva evolucionária (Buss et al., 1999) que apontaria para eventuais diferenças, pelo menos ao nível da variável sexo, em termos de tolerância à infidelidade, deparamo-nos com a ausência de diferenças estatisticamente significativas por sexo nessa variável. De facto, os nossos resultados contrariam os resultados de Lavelle (2013) que verificou que a tolerância à infidelidade emocional foi menor nas mulheres, ao passo que nos homens, a tolerância à infidelidade sexual foi menor, numa situação de traição. Já Sabini e Green (2004) também não identificaram diferenças entre sexos no que toca à tolerância à infidelidade, apesar de ter verificado ser mais provável ambos saírem da relação no caso de uma infidelidade emocional.

Outros estudos (Harris, 2003; Lishner, Nguyer, Stocks e Zilmer, 2008; Carpenter, 2012; Urooj, Haque e Anjum, 2015) encontraram resultados semelhantes, contrariando a teoria evolucionária. Um aspeto que parece ser muito relevante e que pode ter condicionado a ausência de diferenças por sexo, a este nível, no nosso estudo, diz respeito ao facto do estudo de Lavelle (2013) ter implicado a leitura prévia de vinhetas descrevendo uma situação de traição sexual e outra de traição emocional e o preenchimento de uma escala de afeto, antes do preenchimento da ETI. Apesar de outros estudos (que não encontraram diferenças por sexo) usarem metodologias semelhantes, no geral, recorrem a itens hipotéticos de traição ("imaginar o/a seu/sua parceiro/a a ter relações sexuais com outra pessoa"), questionando, de seguida, se os respondentes tolerariam ou não a traição, muito à semelhança do que fizemos no presente estudo.

Já no estudo de Lavelle (2013), a leitura de vinhetas bastante vívidas e explícitas no que toca a uma hipotética situação de infidelidade ["O João chegou a casa e ouviu barulho vindo da sala. Fica claro que a mulher e um amigo estão a conversar animadamente. Ao aproximar-se da sala, ouve claramente a mulher a dizer "eu também te amo (...)"], pode aumentar a probabilidade de identificação com a pessoa que é traída, facilitando a que quem lê realmente se coloque na situação como se a estivesse a viver. Para além disso, na vinheta é tido em conta o sexo de que trai e de quem é traído, aumentando mais o potencial referido de identificação, o que pode tornar mais salientes as diferenças de resposta às questões, atendendo ao sexo dos sujeitos. Assim, no futuro, seria interessante, recorrendo à versão adaptada Portuguesa da ETI, e recorrendo a uma metodologia idêntica à utilizada por Lavelle (2013), testar diferenças por sexo na tolerância à infidelidade, bem como associações com outras variáveis (algumas que incluímos e outras que podiam ter sido consideradas).

Em relação às potenciais associações entre diferentes variáveis sociodemográficas, relacionais e relativas à infidelidade (e perdão face à mesma) e a tolerância à infidelidade, os sujeitos casados ou a coabitarem apresentaram maior tolerância à infidelidade sexual. Lavelle (2013) também concluiu que os homens casados têm maior probabilidade de tolerar os dois tipos de infidelidade (emocional e sexual), em comparação com as mulheres.

No nosso estudo, dado não termos encontrados diferenças por sexo na tolerância à infidelidade, exploramos esta associação na amostra total, constatando que estar casado ou viver em união de facto parece conduzir a uma maior tendência para tolerar a infidelidade em ambos os sexos. Este resultado pode relacionar-se com a presença de um compromisso, investimento emocional e eventual dependência financeira e emocional que os sujeitos casados podem apresentar, em comparação com os indivíduos solteiros. Isto pode levá-los a, mais facilmente, tolerar a infidelidade (não podendo ser esquecida a eventualidade da presença de filhos poder 
estar associada, também, a esta maior tolerância face à traição). Vários autores referem a questão do compromisso, dependência (dos dois tipos) e a preocupação com o bem-estar dos filhos, como varáveis que aumentam a probabilidade de tolerar a infidelidade (Bornstein, 2006; Cann e Baucom, 2004; Poortman e Seltzer, 2007). No estudo de Viegas e Moreira (2013), os indivíduos solteiros (que nunca namoraram ou nunca estiveram numa relação) revelaram tolerar mais a traição, o que, apesar de poder parecer contraditório, pode fazer algum sentido, dado que o desconhecimento das variáveis envolvidas quando se está num relacionamento (compromisso, dependência, entre outras variáveis) por alguém que nunca teve nenhum, pode conduzir a uma desvalorização das situações de infidelidade e do seu verdadeiro impacto.

Quanto ao facto de, na nossa amostra, os participantes que perdoarem a traição terem maior tolerância à infidelidade sexual e aqueles que consideraram não ter sido difícil perdoar terem maior tolerância à infidelidade sexual e emocional, estes resultados apontam para a validade de construto da ETI (permitindo, indirectamente, explorar a sua validade convergente) e estão de acordo com o estudo de Shackelford, Buss e Bennett (2002) que mostrou que, em ambos os sexos, uma menor facilidade em perdoar, levaria a uma maior probabilidade de sair da relação tendo havido uma traição sexual.

Estaríamos à espera que variáveis como "ter traído" ou "saber ter sido traído" pudessem ter revelado associações com a tolerância à infidelidade. De facto, Lavelle (2013) referiu que o facto da pessoa já ter sido traída ou ter traído influencia a probabilidade de a infidelidade ser tolerada. Porém, tal não se verificou no nosso estudo. Voltamos a considerar a metodologia utilizada nos estudos antes da administração da ETI como um elemento que pode condicionar estes resultados.

Numa perspetiva evolucionária, estaríamos à espera que níveis mais baixos de tolerância à infidelidade se associassem a níveis mais elevados de autocriticismo e menores de autocompaixão, tendo em conta que menores níveis de autocompaixão e maiores de autocriticismo dificultam a capacidade de tolerar as próprias falhas e erros, mas também as falhas e erros dos outros, como sucede numa situação de traição (Zuroff, Moskowitz e Côté, 1999; Neff, 2003b; Thompson e Zuroff, 2004).

Talvez pudesse ter sido uma melhor opção o recurso a medidas focadas na compaixão (face ao outro) e crítica face ao outro (e.g. medidas de perfecionismo orientado para o outro) e, ao mesmo tempo, a resposta a estas outras medidas ou mesmo à FSCRS e à SELFCS tendo como "erro de base" do outro ou do próprio uma situação de traição (em vez da resposta genérica sobre como lidam consigo próprios/com os outros face a inadequações, erros e/ou fracassos).

Tendo já acentuada a importância dos dados preliminares de validação da ETI, não podemos deixar de mencionar as limitações principais deste estudo e referir hipóteses de estudos futuros. A nossa amostra não pode ser considerada representativa da população portuguesa, ao tratar-se de uma amostra de conveniência (de acentuar a necessidade de, no futuro, existir um maior equilíbrio no número de sujeitos do sexo feminino e masculino). Tal diminui a validade externa do estudo e condiciona a generalização dos resultados. Num estudo sobre um tema relativo à área da infidelidade, embora que não exatamente sobre infidelidade, a metodologia de recolha de dados (online e através de instrumentos de autorelato), apesar de ter assegurado o anonimato e confidencialidade dos mesmos, precisamente pelo tema em causa, pode ter condicionado os resultados.

Já referimos a metodologia utilizada na avaliação da tolerância à infidelidade, visto que o não recurso a situações ativadoras da identificação do sujeito com a pessoa que foi traída, antes do preenchimento da ETI, pode não ter permitido avaliar de forma precisa a tolerância à infidelidade (no caso da mesma acontecer).

Muitas outras variáveis poderiam ter sido exploradas em associação com a tolerância à infidelidade, como a religião, as opiniões políticas, os traços de personalidade e os estilos de vinculação, o que pretendemos fazer em estudos futuros. Importa, ainda, refletir, sobre a importância de serem realizados mais estudos sobre o tema da tolerância à infidelidade, uma vez que, se parecem existir resultados positivos associados ao recurso à terapia de casal em situações de infidelidade (Atkins, Marín, Lo, Klann e Hahlweg, 2010), importa explorar melhor as variáveis que influenciam a tolerância (ou não) à infidelidade e que podem, se o casal assim o entender, constituir focos centrais da terapia.

Conflito de interesses | Conflict of interest: nenhum | none.

Fontes de financiamento | Funding sources: nenhuma | none.

\section{REFERÊNCIAS}

Afifi, W.A., Falato, W.L. e Weiner, J.L. Identity concerns following a severe relational transgression: The role of discovery method for the relational outcomes of infidelity. Journal of Social and Personal Relationships, 18(2), 291-308.

Allen, E.S. e Baucom, D.H. (2006). Dating, marital and hypothetical extradyadic envolvements: How do they compare. The Journal of Sex Research, 43(4), 307-317.

Almeida, L. S. e Freire, T. (2008). Metodologia da investigação em psicologia e educação ( $4^{\mathrm{a}}$ ed.). Braga: Psiquilíbrios Edições.

Amato, P.R. e Previti, D. (2003). People's reasons for divorcing. Journal of Family Issues, 24,(5), 602-626. 
Atkins, D.C., Baucom, D.H. e Jacobson, N.S. (2001). Understanding Infidelity: correlates in a national random sample. Journal of Family Psychology, 15(4), 735-749.

Atkins, D.C., Marín, R.A., Lo, T.T., Klann, N. e Hahlweg, K. (2010) Outcomes of couples with infidelity in a community-based sample of couple therapy. Journal of Family Psychology, 24(2), 212-216.doi: 10.1037/ao018789.

Baskin, T.W. e Enright, R. D. (2004). Intervention studies on forgiveness: A meta-analysis. Journal of Counseling and Development, 82, 79-80.

Blow, A.J. e Hartnett, K. (2005). Infidelity in committed relationships II: a substantive review. Journal of Marital and Family Therapy, 31(2), 217233.

Bornstein, R.F. (2006). The complex relationship between dependency and domestic violence: Converging psychological factors and socia forces. American Psychologist, 61, 595-606.

Buscher, T. (2012). Memórias emocionais, Autocriticismo e Alexitimia: que contributo para a Psicopatologia. Dissertação de mestrado não publicada, Universidade de Coimbra, Faculdade de Psicologia e de Ciências de Educação, Coimbra.

Buss, D.M. (1995). Psychological sex differences: Origins through sexual selection. American Psychologist, 50(3), 164-168.

Buss, D.M., Larsen, R.J., Westen, D. e Semmelroth, J. (1992). Sex differences in jealousy: Evolution, physiology, and psychology. Psychological Science, 3, 251-255.

Buss, D.M. e Shackelford, T.D. (1997). Susceptibility to Infidelity in the first year of marriage. Journal of Research in Personality, 31, 193-221.

Buss, D.M., Shackelford, T.K., Kirkpatrick, L.A., Choe, J.C., Lim, H.K., Hasegawa, M., ... Bennett, K. (1999). Jealousy and the nature of beliefs about infidelity: Tests of competing hypotheses about sex differences in the United States, Korea, and Japan. Persona Relationships, 6(1), 125-150.

Cann, A. e Bacuom, T.B. (2004). Former partners and new rivals as threats to a relationship: Infidelity type, gender and commitment as factors related to distress and forgiveness. Personal Relationships, 11, 305-318.

Carpenter, C.J. (2012). Meta-analyses of sex differences in responses to sexual versus emotional infidelity: Men and women are more similar than different. Psychology of Women Quarterly, 36(1), 25-37.

Castilho, P. (2011). Modelos de relação interna: Autocriticismo e Autocompaixão. Uma abordagem evolucionária compreensiva da sua natureza, função e relação com a psicopatologia. Dissertação de doutoramento, Faculdade de Psicologia e de Ciências da Educação da Universidade de Coimbra, Coimbra.

Castilho, P., Gouveia, J.P. e Amaral, V. (2010). Recordação das experiências de ameaça e subordinação na infância e psicopatologia: o efeito mediador do auto-criticismo, Psychologica, 52(2), 475-498.

Castilho, P. e Pinto Gouveia, J. (2011a). Autocriticismo: Estudo de validação da versão portuguesa da escala das formas do autocriticismo e autotraquilização (FSCRS) e da escala das funções do autocriticismo e autoataque (FSCS). Psychologica, 54, 63-86.

Castilho, P. e Pinto Gouveia, J. (2011b). Autocompaixão: Estudo da validação da versão portuguesa da escala da autocompaixão e da sua relação com as experiencias adversas na infância, a comparação social e a psicopatologia. Psychologica, 54, 203-230.

Catell, R.B. (1966). The scree test for number of factors. Multivariate Behavioral Research, 1, 245-276.

Cohen, J. (1992). A power prime. Psychological Bulletin, 112(1), 155-159. Obtido em http://drsmorey.org/bibtex/upload/Cohen:1992.pdf.

DiBlasio, F.A. (2000). Decision-based forgiveness treatment in cases of marital infidelity. Psychotherapy, 37, 149-158.

Drigotas, S.M. e Barta, W. (2001). The cheating heart: Scientific explorations of infidelity. Current Directions in Psychological Science, 10(5), 177-180.

Drigotas, S.M., Safstrom, C.A. e Gentilia, T. (1999). An investment model prediction of dating infidelity. Journal of Personality and Social Psychology, 77, 509-524.
Fife, S.T., Weeks, G.R. e Stellberg-Filbert, J. (2013). Facilitating forgiveness in the treatment of Infidelity: an interpersonal model. Journal of Family Therapy, 35, 343-367.

Finkel, E.J., Rusbult, C.E., Kumashiro, M. e Hannon, P.A. (2002). Dealing With Betrayal in Close Relationships: Does Commitment Promote Forgiveness? Journal of Personality and Social Psychology, 82(6), 956 974.

Flanigan, C. M. (2007). Staying with a partner who cheats: The influence of gender and relationship Dynamics on adolescents' Tolerance of Infidelity. Dissertação de mestrado, Universidade Bowling Green State, Estados Unidos.

Galperin, A., Haselton, M.G., Frederick, D.A., Poore, J., Hippel, W.V., Buss, D.M. e Gonzaga, G. C. (2013). Sexual Regret: Evidence for Evolved Sex Differences. Archives of Sexual Behaviour, 42(7), 1145-1161.

Gilbert, P. (2005). Compassion and cruelty: A biopsychosocial approach. In P. Gilbert (Ed.), Compassion: Conceptualisations, research and use in psychotherapy (pp. 9-74). London: Routledge.

Gilbert, P., Clarke, M., Hempel, S., Miles, J., e Irons, C. (2004). Criticizing and reassuring oneself: An exploration of forms, styles and reasons in female students. The British Jounal of Clinical Psychology, 43(1), 3150.

Hall, J.H. e Fincham, F.D. (2006). Relationship dissolution following Infidelity: the roles of attributions and forgiveness. Journal of Social and Clinical Psychology, 25(5), 508-522.

Harris, C.R. (2003). Factors associated with jealousy over real and imagined infidelity: An examination of the social-cognitive and evolutionary psychology perspectives. Psychology of Women Quarterly, 27, 319-329.

Kaiser, H. (1970). A second generation: Little Jiffy. Psychometrika, 35, 401415.

Kaiser, H. (1974). An index of factorial simplicity. Psychometrika, 39, 31-3

Kerlinger, F.N. (1986). Foundations of behavioral research (3rd ed.). New York: Holt, Rinehard and Winston.

Lavelle, S. (2013). Tolerance for Infidelity: Exploring the factors that determine a person's likehood of staying in a relationship where infidelity has occurred. Dissertação de doutoramento, Universidade de Adelphy, Estados Unidos da América.

Lewandowsky, G.W. e Ackerman, R.A. (2006). Something's Missing: Need fulfillment and self expansion as predictors of susceptibility to infidelity. The Journal of Social Psychology, 146(4), 389-403.

Lishner, D.A., Nguyen, S., Stocks, E.L. e Zillmer, E. J. (2008). Are sexua and emotional infidelity equally upsetting to men and women? Making sense of forced-choice responses. Evolutionary Psychology, 6(4), 667-675.

Luo, S., Cartun, M.A. e Snider, A. G. (2010). Assessing extradyadic behaviour: A review, a new measure, and two new models. Personality and Individual Differences, 49, 155-163.

Mark, K.P., Janssen, E. e Milhausen, R.R. (2009). Infidelity in heterossexual couples: demographic, interpersonal, and personalityrelated predictors of extradyadic sex. Archives of sexual behavior, 40(5), 971-982.

Martins, A.F.R.S. (2012). Comportamentos extra-diádicos offline e online nas relações de namoro: Diferenças de género nos motivos, prevalência e correlatos. Dissertação de mestrado não publicada, Universidade de Coimbra, Coimbra.

Miller, S.L. e Maner, J.K. (2009). Sex differences in response to sexua versus emotional infidelity: The moderating role of individual differences. Personality and individual differences, 46, 287-291.

Neff, K.D. e Pommier, E. (2013). The relationship between selfcompassion and other-focused concern among college undergraduates, community adults, and pacticing meditators. Self and Identity, 12(2), 160-176. http://doi.org/10.1080/15298868.2011.649546

Neff, K.D. (2003a). Development and validation of a scale to measure self-compassion. Self and Identity, 2, 223-250.

Neff, K.D. (2003b). Self-compassion: An alternative conceptualization of a healthy attitude toward oneself. Self and Identity, 2, 85-102. 
Pais-Ribeiro, J.L. (2010). Metodologia de investigação em psicologia e saúde (3. ${ }^{\text {a ed. }}$ ). Porto: Legis Editora.

Pallant, J. (2007). SPSS: Survival manual (3rd ed.). New York: Open University Press.

Pasquali, L. (2003). Psicometria - Teoria dos Testes na Psicologia e Educação. Petrópolis: Editora Vozes.

Pestana, M.H. e Gageiro, J.N. (2008). Análise de dados para ciências sociais: a complementaridade do SPSS ( 5 ed.). Lisboa: Edições Sílabo.

Poortman, A.R. e Seltzer, J.A. (2007). Parents' Expectations About Childrearing After Divorce: Does Anticipating Difficulty Deter Divorce? Journal of Marriage and Family, 69(1), 254-269.

Sabini J. e Green, M.C. (2004). Emotional responses to sexual and emotional infidelity: constants and diferences across genders, samples, and methods. Society for Personality and Social Psychology, 30(11), 1375-1388. doi: 10.1177/0146167204264012.

Sagarin, B.D., Becker, D.V., Gaudagno, R.E., Nicastle, L.D. e Millevoi, A. (2003). Sex differences and similarities in jealousy: The moderating influence of infidelity experience and sexual orientation of the infidelity. Evolution and Human Behaviour, 24, 17-23.

Shackelford, T.K. e Buss, D.M. (1997). Antecipation of marital dissolution as a consequence of spousal Infidelity. Journal of Social and Personal Relationships, 14(6), 793-808.

Shackelford, T.K. (1997). Divorce as a consequence of spousal infidelity. Journal of Social and Personal Relationships, 14(6), 793-80.

Shackelford, T.K., Buss, D.M. e Bennett, K. (2002). Forgiveness or breakup: Sex differences in responses to a partner's infidelity. Cognition and Emotion, 16(2), 299-307.

Shackelford, T.K, Besser, A. e Goetz, A.T. (2008). Personality, marital satisfaction and probability of marital Infidelity. Individual Differences Research, 6(1), 13-25.
Shackelford, T.K., LeBlanc, G.K. e Drass, E. (2000). Emotional reactions to infidelity. Cognition and Emotion, 14(5), 643-659.

Thompson, A. P. (1983). Extramarital sex: A review of the research literature. Journal of Sex Research, 19, 1-22.

Thompson, R. e Zuroff, D.C. (2004). The levels of self-criticism scale: comparative self-criticism and internalized self-criticism. Personality and Individual Differences, 36, 419-430.

Treas, J. e Giesen, D. (2000). Sexual Infidelity among married and cohabiting americans. Journal of Marriage and The Family, 62, 48-60.

Tsapelas, I., Fisher, H. e Aron, A. (2010). Infidelity: when, where, why. In W. R. Cupach e B.H. Spitzberg, The Dark Side of Close Relationships II, New York: Routledge, pp. 175-196.

Urooj, A., Haque, A. e Anjum, G. (2015). Perception of emotional and sexual infidelity among married men and women. Pakistan Journal of Psychological Research, 30(2), 421-439.

Viegas, T. e Moreira, J.M. (2013). Julgamentos de infidelidade: Um estudo exploratório dos seus determinantes. Estudos de Psicologia, 18(3), 411-418.

Whisman, M. A., Dixon, A. E., e Johnson, B. (1997). Therapists' perspectives of couple problems and treatment issues in couple therapy. Journal of Family Psychology, 11, 361-366.

Yarnell, L.M., Stafford, R.E., Neff, K.D., Reilly, E.D., Knox, M.C. e Mullarkey, M. (2015). Meta-analysis of gender differences in selfcompassion. Self and Identity, 14(5), 499-520. DOI: 10.1080/15298868.2015.1029966.

Zuroff, D. C., Moskowitz, D.S. e Côté, S. (1999). Dependency, selfcriticism, interpersonal behavior and affect: Evolutionary perspectives. British of Clinical Psychology, 38, 231-250. doi: $10.1348 / 014466599162827$ 